\title{
Possibilitando leituras diagramáticas dos resumos de teses: um caça-sentido à pesquisa em design no Brasil
}

\author{
Roberta Rech Mandelli; \\ Douglas Onzi Pastori; \\ Marcelo Vianna Batista
}

resumo:

Entre 2004 e 2019, os programas de poś-graduação em design no Brasil produziram 423 teses que titularam seus autores como doutores em design. Sobre o que versaram essas pesquisas? Quais temáticas desenvolveram? A partir do interesse pela emergência de termos situados em textos cujas temáticas parecem escapar às discussões dominantes da área do design, recorre-se à ferramenta de visualização de dados bibliométricos VOS Viewer para, além de suas possibilidades de uso convencionais, poder gerar diagramas dos temas que são menos recorrentes nos resumos das teses (corpus textual específico desta pesquisa). Assim, desenvolve-se uma classificação e discussão semiótica acerca tanto dos resumos quanto das visualidades encontradas. Por fim, entende-se os mapas como sensibilizações iniciais, índices que tornam visíveis temáticas emergentes as quais podem inspirar e apontar outros caminhos de investigação em design aos pesquisadores em formação.

\section{palavras-chave:}

pós-graduação em design; semiótica; diagrama; bibliometria; peritextos 
Revire o livro entre as mãos, percorra o texto da contracapa, das orelhas, são frases genéricas que não dizem muito. Melhor isso que um discurso que pretenda sobrepor-se de forma indiscreta àquele que o livro deve comunicar diretamente, àquilo que, pouco ou muito, você mesmo extrairá dele. É certo que esse passeio ao redor do livro - ler o que está fora antes de ler o que está dentro - também faz parte do prazer da novidade, mas, como todo prazer preliminar, este também deve durar um tempo conveniente e pretender apenas conduzir aos prazer mais consistente, à consumação do ato, isto é, à leitura do livro propriamente dito.

Italo Calvino

\section{Como Diagramatizar Todas as Teses de Design do Brasil?}

A presente pesquisa parte do pressuposto situacional da demanda lançada para a turma do segundo semestre letivo de 2018, na disciplina de Projetos Doutorais em Design do curso de Doutorado em Design do Programa de Pós-Graduação em Design da Universidade do Vale do Rio dos Sinos (UNISINOS). O conteúdo proposto solicitava um mapeamento dos temas de pesquisa das teses apresentadas pelos doutorados dos PPGs de Design brasileiros desde sua implementação a partir do pioneirismo da Pontifícia Universidade Católica do Rio de Janeiro, em $2003^{1}$.

Levantado o corpus correspondente à demanda - 423 teses - alguns desafios teóricometodológicos logo se mostraram ao gigantismo da análise pretendida. O percurso que melhor atende à solicitação, requer uma análise do conteúdo semântico de todas as teses, exigindo uma leitura e interpretação exegética de um total, aproximadamente, de 63.440 páginas e 25.380 .000 palavras (levando em conta que cada tese tenha em média 150 páginas de texto e que cada página apresenta em torno de 400 palavras). Se cada página levar meio minuto de leitura, seriam necessários, aproximadamente, 528 horas de leitura, ou então, quase 22 dias de leitura ininterrupta. Evidentemente, a demanda cognitiva de tal empreitada não coube na solicitação da tarefa da referida disciplina, cabendo ela ser realizada por futuras pesquisas caso haja pesquisadores humanos capazes e confortáveis em fazê-la, ou então assistidos por máquinas semanticamente competentes em análise e interpretação de textos, caso em que as learning machines ainda não se mostraram atuantes.

Portanto, diante da precariedade dos insumos necessários à solução da tarefa requerida que inviabiliza o recurso imediato aos textos de base, o acesso mediato a elas só pode ser indiciado por elementos periféricos a estes textos. Genette (2009) os denomina de peritextos, isto é, textos coadjuvantes que orbitam o corpus dos textos principais, classificados pela generalidade mais ampla de paratextos, ou seja, de textos que se posicionam ao lado, nas franjas de outros textos.

No caso dos textos de tese, tem-se, obrigatoriamente, segundo normatização da Associação Brasileira de Normas Técnicas (ABNT), elementos pré-textuais, tais como títulos e subtítulos, resumos em língua portuguesa e estrangeiras, palavras-chave, listas (de abreviaturas, de siglas, de tabelas, de quadros e ilustrações), sumarização das seções do texto, e, opcionalmente, epígrafes e agradecimentos, bem como elementos pós-textuais, tais como a ordenação das referências múltiplas, os apêndices e anexos do texto em questão. Ao alinhar conceitualmente a noção de elementos prétextuais e pós-textuais aos conceitos de peritexto e paratexto de Genette (2009), posto que se constituem de elementos textuais que orbitam o texto principal, auxiliando a orientação de sua leitura, nas cercanias dos textos de tese, é possível, de modo indireto, alcançar as redondezas do seu conteúdo semântico, tendo sempre em mente que, consoante tal procedimento, o sumo desse conteúdo fica inviabilizado de ser analiticamente investigado.

Dentre as opções peritextuais das teses doutorais, opta-se pela utilização dos resumos que, decompostos e recompostos em um software (VOS Viewer) a partir de lógicas bibliométricas, fazem

\footnotetext{
${ }^{1}$ A PUC RIO, como pioneira da pós-graduação em design no Brasil, iniciou em 1994 seu primeiro curso de mestrado em design.
} 
surgir palavras na superfície de um mapa cartográfico ${ }^{2}$, cuja legibilidade diagramática depende da conversão do arquivo dos peritextos originais em um ícone/índice visual. Assim, desarticuladas de seu plano semântico ordenador, isto é, de seu programa textual, as palavras podem surgir como significantes icônicos que prefiguram a legitimação de uma leitura mais categórica. Essa desarticulação parcial (nunca completa, diga-se de passagem), revela o prejuízo de obter qualquer análise peremptória do corpus em questão, mas viabiliza outros valores possíveis, desvinculados da (pro)gramática das teses stricto sensu, entretanto, que, de qualquer modo, as tangencia, revelando a sutileza da mera repetição material das palavras numa seqûencia de letras que pretende circunscrever um sentido a ser lido sempre por vir.

Que haja um programa, um sistema gramatical ordenador, isso é uma condição a priori para possível leitura de um plano semântico, caso contrário, o regime estocástico de signos e sua atualização aleatória denotaria um sistema onde o sentido se apresenta desvinculado de uma intencionalidade semantizadora ${ }^{3}$. E é à espreita dessas in-tensões entre as expressões peritextuais das palavras que circunscrevem os domínios semânticos de um, possivelmente coerente (ou não), campo de pesquisa em design, que estes diagramas, enquanto mapas, pretendem se posicionar.

Ainda, é importante salientar que o interesse deste artigo reside na emergência das temáticas do campo, mais do que nas que já se encontram consolidadas. Isso porque, dentre todas possibilidades que a linguagem diagramática oferece, considera-se, prioritariamente, o seu caráter de abertura sígnica às outras interpretações, fazendo ela sempre vislumbrar algo alhures, para além do domínio habitual do óbvio, tornando-se interessante ao processo criativo, necessariamente abdutivo, da pesquisa em design (o que não o exime de uma rigorosa coerência metalinguística).

Caso haja críticos, ou mais que críticos, céticos dessa possibilidade enviesada de leitura dos temas das pesquisas do corpus problematizado, a apreciação do artigo que se segue se torna impossível. Para todos os demais críticos, o diálogo vindouro será bem acolhido.

Na próxima seção, aborda-se o conceito dos peritextos em diálogo com as categorias sígnicas peircianas: a base teórica que é a chave tanto da composição (ver terceira seção) quanto da leitura (ver quarta seção) dos diagramas. Por fim, a quinta seção se ocupa das considerações finais.

\section{Negociações Semióticas}

Esta passagem metodológica dos paratextos aos mapas diagramáticos solicita não só um desvio de percurso técnico-procedimental mas também epistemológico. Assim, do domínio estruturalista da textualidade onde, primeiramente, a investigação se instala pela via teórica de Genette $(2009,2010)$, solicita-se um desenvolvimento pela fenomenologia pragmática de Peirce (1984) e sua análise das classes lógicas de signos. Ambas epistemologias semióticas se encontram no esteio do objetivismo idealista pós-kantiano, porém, por caminhos próprios, erigiram diferentes teorias, as quais, neste momento, demandam um encontro diplomático em forma de um consenso parcial que não oblitera, em pretensa resolução teórica alguma, os polêmicos dissensos de origem, para que as possibilidades dessa investigação façam sentido. Portanto, solicita-se que a cortina de ferro entre as epistemologias seja relativamente recolhida a fim de que essas vias de negociação teórico-metodológicas sejam possíveis

\footnotetext{
${ }^{2}$ A especificidade teórica dos mapas cartográficos ou diagramas emergentes se singulariza no neologismo assim denominado - fenogramas - isto é, a letra de uma palavra inscrita em um texto que aparece dele deslocada mas que permite a possibilidade de uma leitura outra. $\mathrm{O}$ estatuto sígnico dos fenogramas só pode se dar de modo litigioso, fazendo de sua análise e interpretação, um recurso de mediação para o debate, e não o seu ponto final.

${ }^{3}$ Sem a chave de leitura adequada, tais palavras se tornam um código inacessível de ser compreendido, mais ou menos como eram os hieróglifos egípcios antes da descoberta da Pedra de Roseta, pois sua condição pictogramática demandava um meio de decifragem que os arqueólogos modernos desconheciam antes que essa pedra fosse descoberta e, por comparação com as gramáticas hebraicas e gregas dos para-textos egípcios inscritos em tal pedra, pode então, ser lida, bem como a totalidade do sistema gramatical dos antigos hieróglifos. A decifragem tornou estes signos legíveis, ao mesmo tempo extraindo e retirando de seu contexto sagrado de outrora (hiero-gliphos, do grego, escritas sagradas), tal como a decifragem de um criptograma, cuja abertura profanadora do código permite que suas informações escondidas (do grego, cripto-gramma, letra escondida) possam ser compartilhadas e comunicadas, viabilizando uma leitura mais livre.
} 
e, com elas, objetos de estudo idiossincráticos como este, possam ser acolhidos na luz da compreensão lógico-científica da pesquisa semiótica.

A partir da noção de palimpsesto, isto é, do resultado de uma prática de escrita que se inscreve sobre o encobrimento parcial do registro de outra escrita (comum entre os escribas e a economia de pergaminhos da Idade Média), Genette (2010) teoriza sobre múltiplas classes de transtextualidades no esteio do reconhecimento das intertextualidades do regime literário de escrita estudadas sobretudo por Kristeva e Rifaterre ${ }^{4}$, bem como das paratextualidades caracterizadas pelo uso de elementos estratégicos da relação contratual, logo, de ordem pragmática, entre escrita e leitura, em prol da veiculação pública de um texto, tais como:

[...] título, subtítulo, intertítulos, prefácios, posfácios, advertências, prólogos, etc.; notas marginais, de rodapé, de fim de texto; epígrafes; ilustrações; release, orelha, capa, e tantos outros tipos de sinais acessórios, autógrafos ou alógrafos, que fornecem ao texto um aparato (variável) e por vezes um comentário, oficial ou oficioso, do qual o leitor, o mais purista e o menos vocacionado à erudição externa, nem sempre pode dispor tão facilmente como desejaria e pretende. (GENETTE, 2010, pg. 15)

Para além destas duas tipologias de transtextualidades, há que se considerar também as metatextualidades, constituídas majoritariamente de comentários (sem a obrigação da citação ou quaisquer outras convocações imediatas) a um determinado texto: "É, por excelência, a relação crítica." (GENETTE, 2010, pg. 17); bem como as arquitextualidades, ${ }^{5}$ isto é, as relações de caráter basicamente taxonômico que subscrevem a ordem genérica de produção dos textos (tipos de discurso, modos de enunciação, gêneros literários, etc.). E por fim, Genette caracteriza as hipertextualidades, ou seja, toda relação textual excluída da ordem do comentário (logo, da crítica), que liga, de modo geneticamente derivativo, um texto (hipertexto) a outro texto (hipotexto) do qual, obviamente, do precedente, adveio.

Há um exemplo curioso de hipertextualidade que aqui pode ser ilustrativo: "como leríamos o Ulysses de Joyce se não se intitulasse Ulysses?" (GENETTE, 2009, pg. 20) Genette explicita o caso da palavra Ulysses aparecer como título do grande "romance" de James Joyce, tomando a nominação desta obra por referência direta à Odisséia homérica, o que viabiliza uma chave de leitura do opus magnum do modernismo a partir de uma paralaxe anacrônica das aventuras de Leopold Bloom por Dublin em relação à epopéia arcaica grega de Ulisses retornando à Ítaca depois da Guerra de Tróia. Nesse sentido, a aparição de uma palavra em um texto, por mais aleatória que o seja, dificilmente seja desprovida totalmente de sentido, seja ele qual for. Assim, as classes de textualidade acima elaboradas por Genette auxiliam à compreensão de alguns sentidos possíveis, desde que conservem a imanência à classe transtextual, isto é, aquela capaz de compreender todas as outras.

Se o título é uma pista relevante das estratégias adotadas pelos escritores à pragmática da leitura, em textos científicos, outras pistas também se encontram nessa zona estratégica fronteiriça que envolve e reveste o espaço interior do texto, distinguindo-o do espaço extra-textual de sua acolhida no mundo verbal da escrita e da leitura acadêmica, afinal, "pode-se sem dúvida adiantar que não existe, e que jamais existiu, um texto sem paratexto." (GENETTE, 2009, pg.11). Nesse sentido, a obrigatoriedade normatizadora dos resumos em trabalhos científicos, faz deles um paratexto por excelência, cuja tematização entre o miolo do texto científico, isto é, a enunciação da tese, e a sua apreciação pelos pares do campo acadêmico-científico - os leitores -, o converte em um elemento estratégico para a captura do sentido do bojo texto. Logo, do que se trata, efetivamente, um paratexto?

Um elemento de paratexto, se pelo menos consiste numa mensagem materializada, tem necessariamente um lugar, que se pode situar em relação àquela do próprio texto: em

\footnotetext{
${ }^{4}$ Genette (2010) os referencia como: KRISTEVA. Semeiotike: recherches pour une sémanalyse e RIFATERRE. La production du texte e Sémiotique de la poésie.

5 A origem mais precisa das teorizações sobre o conceito de arquitexto é desenvolvida em The Architext: An Introduction, onde Genette (1992) o elabora a partir da Poética de Aristóteles.
} 
torno do texto, no espaço do mesmo volume, como o título ou o prefácio, e, às vezes, inserido nos interstícios do texto, como os títulos de capítulo ou certas notas; chamarei de peritexto essa primeira categoria espacial (...). Ainda em torno do texto, mas a uma distância mais respeitosa (ou mais prudente), todas as mensagens que se situam, pelo menos na origem, na parte externa do livro: em geral num suporte midiático (conversas, entrevistas), ou sob a forma de uma comunicação privada (correspondências, diários íntimos e outros). A essa segunda categoria eu batizo, na falta de um termo melhor, de epitexto (...). Como deve, doravante, ser automático, peritexto e epitexto dividem entre si, exaustivamente e sem descanso, o campo espacial do paratexto; dito de outra forma, para os amantes de fórmulas, paratexto = peritexto + epitexto". (GENETTE, 2009, pg. 11)

Portanto, é nesse jogo de remissões de significação da ordem de um modo de existência verbal sob o registro de um materialização textual, que as palavras escritas de um resumo se constituem de um peritexto que franjeia o texto de uma tese científica. Traduzir essa modalidade de existência para uma outra, conforme a possibilidade de um outro registro, significa borrar o texto original, apagá-lo e, ao prejuízo de uma rasura, sombreá-lo sob uma nova inscrição dele desvirtuada? Ou será possível conservar traços mínimos do sentido original, respeitando uma certa margem de adulteração que convoque, ainda, o sentido de verdade que esse palimpsesto (e todos os outros possíveis) não consegue, jamais, anular? Em outras palavras, é possível modificar o aspecto textual da existência sígnica de um peritexto na aparição imagética de seus termos em um diagrama? Se Genette não lança luz sobre essa possibilidade, sob a ameaça de romper com o domínio epistemológico da textualidade, quem sabe a semiótica fenomenológica peirceana o permita.

Para Peirce um signo "é algo que, sob certo aspecto ou de algum modo, representa alguma coisa para alguém" (1984, p.94). Isso que o signo representa - "alguma coisa" - é chamado de objeto que, por sua vez, existe "para alguém", chamado de interpretante. Tem-se assim a tríade semiótica signo-objeto-interpretante. Toda a semiótica peirciana se constrói a partir de tríades, que advém dos princípios fenomenológicos ${ }^{6}$ que estruturam o pensamento do autor. Assim, Peirce (1984) propõe três tricotomias de classificação dos signos, que podem ser adotadas para descrever quaisqueres que sejam as existências. No entanto, é importante frisar que as classificações a priori significam pouco frente às variedades que a experiência a posteriori apresenta e que, portanto, as divisões não serão de todo idênticas. (PEIRCE, 1984).

A primeira tríade proposta por Peirce (1984) diz respeito ao signo em si e consiste em: (i) quali-signo, a qualidade de uma existência em potencial; (ii) sin-signo, como sinal de uma existência concreta, única, singular e (iii) legi-signo, sendo lei geral, ou seja, não singular. O legi-signo só existe enquanto tal por meio de uma réplica, que é um caso de sua aplicação que lhe outorga significado. A réplica, por sua vez, é uma existência singular, um sin-signo. Logo, só é possível alcançar leis gerais segundo o processo de replicação de ocorrências sígnicas singulares, isto é, de repetição de aparições existenciais dos signos.

Seguindo, tem-se a segunda tríade na dependência da relação do signo com seu objeto, como: (i) ícone, que é um signo que se refere ao seu objeto em si mesmo, ou seja, independente da existência desse objeto (que no entanto deve existir); qualquer uma das classificações anteriores será um ícone na medida em que se assemelha ao seu objeto e o representa; (ii) indice é um signo que se refere ao objeto na medida em que é afetado por ele, ou seja, é diretamente dependente de sua existência; sua relação com o objeto não é apenas de semelhança, mas também é a medida em que o objeto o modifica; (iii) símbolo, como signo que se refere ao objeto por força de um lei, que pode ser uma associação de ideias que remetem ao objeto. (PEIRCE, 1984).

E, por fim, a terceira tríade se estabelece na dependência da relação do signo com seu interpretante, que se define como: (i) rema, signo que é mera possibilidade qualitativa para seu interpretante, ou seja, pode fornecer alguma informação, mas não é destinado a fazê-lo; (ii) dicente que é signo de existência concreta para o interpretante, sendo portanto uma proposição cuja

\footnotetext{
${ }^{6}$ A fenomenologia de Peirce (1984) coloca os princípios da primeiridade, secundidade e terceiridade que se desdobram em suas categorizações semióticas.
} 
peculiaridade reside em seu modo de significar, não precisando ser asseverada; (iii) argumento, que é signo de lei para seu interpretante, ou seja, uma proposição que tenderá sempre para a verdade. (PEIRCE, 1984). Essas três tricotomias de signo definem, por sua vez, dez classes de signos, que representa um contínuo crescente de complexidade, de forma que a classe subsequente sempre comportam, em alguma medida, às classes anteriores.

O que Genette (2009) chama de peritextos, e que denominamos aqui de elementos pré-textuais das teses (títulos, resumos, lista de figuras, etc), são todos, em alguma medida, pertencentes à sétima classe que Peirce (1984) nomeia legi-signo indicativo dicente. Isso porque são todos leis gerais (estabelecidos pelas normas ABNT) que, independente de como se apresentam, exigem que "seja cada um de seus casos realmente afetado por seu Objeto de maneira tal que forneça informação definida, relativamente àquele Objeto" (PEIRCE, 1984, p.106). Ou seja, são legi-signos que são afetados pela tese (objeto) na mesma medida em que fornecem informações sobre ela, como é o caso, por exemplo, de uma lista de figuras.

No entanto, alguns desses elementos pré-textuais possuem graus maiores de complexidade, no sentido de serem interpretados não mais como índices, mas sim como símbolos, ou seja, signos que se relacionam à tese por associações de ideias gerais. É o caso, por exemplo, do título e do resumo, que compõe a nona classe peirciana, o símbolo dicente (legi-signo símbolo dicente). Assim como sua classe anterior (a oitava, que é o símbolo remático) o símbolo dicente se relaciona com o seu objeto pela associação de ideias à diferença que, para o seu interpretante, aquilo que símbolo dicente significa é realmente afeto por seu objeto, "de sorte que a existência ou lei que ele faz surgir no espírito deve estar efetivamente relacionada com o Objetivo indicado." (PEIRCE, 1984, p.107). Sendo assim, o sentido do título e do resumo são, para quem os lê e os escreve, diretamente afetados pela existência da tese ao qual fazem referência.

Os diagramas gerados a partir dos resumos das teses serão discutidos, também sob a luz das categorias Peircianas, no quarta seção deste ensaio. Não se explicita, aqui, quais categorias de signos os diagramas apresentam, por entender que sua leitura só é possível a posteriori desta experiência. Além disso, com intuito de não tornar demasiadamente extenso o artigo, apresentaremos outras classes de signos apenas à medida em que a discussão dos diagramas as solicitar. Antes destes aprofundamentos, a próxima seção se ocupa com a descrição do processo de formulação dos diagramas a serem analisados.

\section{Da Bibliometria à Gramametria: hackeando o software VoS Viewer}

Para conseguir produzir os signos diagramáticos das teses doutorais no Brasil a partir de uma ferramenta de visualização de dados, recorremos a um método de pesquisa reconhecido como Bibliometria. Neste método, pesquisadores embasam suas descobertas em dados bibliográficos agregados, expressos pela citação, colaboração e escrita, em uma "varredura" no documento que busca por citações (ZUPIC; ČATER, 2015). Quando esses dados são agregados e analisados, os insights sobre o campo, sua estrutura, redes sociais e interesses específicos são apresentados. Entre as ênfases distintas, a análise de co-palavras (CALLON et. al., 1983), é uma técnica de análise de conteúdo que usa as palavras em documentos para estabelecer relações e construir uma estrutura conceitual do domínio. A ideia subjacente ao método bibliográfico, independente da ênfase, pressupõe que termos frequentemente co-ocorrem em documentos, e isto significaria que os conceitos por trás deles estão intimamente relacionados. Este pressuposto é algo que se pretende problematizar a partir da análise semiótica dos peritextos.

Pelo caráter polissêmico dos termos, abre-se uma brecha no método bibliográfico para apropriar-se de sua lógica estrutural, a fim de avançar na problematização da leitura dos signos diagramáticos gerados pelas ferramentas desse método. A partir das visualidades que o método bibliográfico permite gerar - em específico a partir do software Vos Viewer - opera-se um hackeamento: de um procedimento conduzido a partir de arquivos que provém de bases 
bibliográficas ${ }^{7}$, que respeitam um rigor estrutural das informações, prossegue-se em direção a uma experimentação de legibilidade dos peritextos pela ferramenta VOS Viewer.

Dessa forma, três passos guiaram o desenvolvimento dos diagramas: (i) a coleta de todas as teses doutorais publicadas no Brasil no período de 2013 a 2019 (ver seção 3.1); (ii) a partir destas, a elaboração de uma base de dados arquiváveis obtidos pela seleção de peritextos das teses (neste caso, os resumos) que pudesse ser interpretada pelo algoritmo do software VOS Viewer (ver seção 3.2); e, por fim, (iii) a geração das imagens visuais, descrita na seção 3.3.

\subsection{Levantamento das Teses em Design no Brasil}

Inicialmente, foi realizada uma busca no Catálogo de Teses e Dissertações da Coordenação de Aperfeiçoamento de Pessoal de Nível Superior (CAPES) ${ }^{8}$, com os filtros doutorado (no campo tipo), arquitetura, urbanismo e design (no campo área de avaliação) e design (no campo nome do programa) resultando em um total de 272 publicações. Essas publicações foram organizadas em uma planilha a partir da seguinte segmentação: instituição de ensaio, título, data de publicação, autor, orientador, área de concentração, linha de pesquisa, palavras-chave e resumo.

Após esse primeiro arquivamento, foram efetuadas buscas nos bancos de dados de todas instituições de ensino que ofertam o curso de Doutorado em Design no Brasil, de forma a complementar o acervo disponível no catálogo de teses da CAPES e evitar que alguma publicação ficasse de fora da seleção (diga-se de passagem, há um grande contingente de teses em design não indexadas no catálogo da CAPES). As instituições que possuem teses publicadas na área do design são as seguintes: Pontifícia Universidade Católica do Rio de Janeiro (PUC-Rio); Universidade Do Estado Do Rio De Janeiro (UERJ); Universidade De São Paulo (USP); Universidade Anhembi Morumbi; Universidade Estadual Paulista Júlio De Mesquita Filho (UNESP); Universidade Do Estado De Minas Gerais (UEMG); Universidade Federal de Pernambuco (UFPE); Universidade Federal Do Paraná (UFPR); Universidade Federal De Santa Catarina (UFSC) e Universidade Federal Do Rio Grande Do Sul (UFRGS).

Os resultados dessa segunda etapa de buscas foram comparados com o levantamento inicial, acrescentando 151 publicações à planilha e resultando assim em um total de 423 teses publicadas até agosto de 2019.

\subsection{Como Criar uma Base de Dados a partir dos Peritextos das Teses}

Quais opções peritextuais se tornam pertinentes a fim de estabelecer a imanência de um plano ainda textual de análise? Em trabalhos acadêmicos, sobretudo os títulos e os resumos. As palavras-chave são um caso especialmente delicado pois incorrem em estratégias de indexação que o enfrentamento da pesquisa do corpus mostrou relações, por vezes, altamente disjuntivas do conteúdo dos peritextos em geral, cabendo a elas alinhamentos políticos desde demandas implícitas dos PPGs até intenções de posicionamento do pesquisador em relação às pesquisas dos pares de campo de pesquisa, o que solicitaria toda uma investigação correspondente às nuances do objeto em questão. Para não delongar em questões vertiginosas, a opção peritextual mais evidente, dentre os elementos normatizadamente obrigatórios, coloca à disposição da atual investigação o título da tese ou o seu resumo. O título também entra em um jogo de disputas pelo uso da linguagem textual de delicada apreciação em relação à generalidade pretendida pela pesquisa da disciplina (evidencialização dos temas dominantes

\footnotetext{
${ }^{7}$ O Vos Viewer exige o uso de bases como a Social Science Citation Index, acessível de maneira online através do Thomson Reuters Web of Science e Scopus, pois tais bases fornecem dados indexados seguindo o rigor daquilo que o método bibliométrico necessita, como por exemplo: título do artigo, autor, categoria de assuntos, etc. A partir destes dados, as filtragens poderão ser realizadas em ferramentas escolhidas para visualização.

8 A CAPES é uma fundação do Ministério da Educação (MEC) que atua na expansão e consolidação da pósgraduação stricto-sensu (mestrado e doutorado) no Brasil.
} 
das pesquisas em design no Brasil), logo, todos esses parâmetros de exclusão textuais e paratextuais constituíram um corpus atualizado pela seletividade peritextual dos resumos em língua portuguesa.

Os resumos, dentre todas as classes alternativas de elementos peritextuais, têm a favorável situação linguística de serem articulados por composições sígnicas concatenadamente lineares - frases, orações, proposições - alinhadas em sintagmas cujos paradigmas semânticos da língua são conservados pela virtualidade de sua potência associativa de comutação. Isto é, os resumos são legíveis como textos que se referem a um outro texto (o texto da tese em si) - acima conceituados como legi-signos simbólicos dicentes (PEIRCE, 1984) - que, por estratégia da técnica peritextual, ausenta-se da aparição imediata da leitura, tornando-se assim um objeto ausente no horizonte imediato deste peritexto, porém não totalmente perdido, já que é seu referente, tal como a silhueta conformada pela área de sombra de um corpo iluminado, logo, seu estatuto ideal é mais adequadamente pensável como virtualizado.

Portanto, a relação que se estabelece entre o texto de tese e o peritexto resumo é também ela paradigmática, rastreável pelas indicações ainda semânticas inscritas na face das palavras que cabe ao resumo resguardar a partir de seu texto de origem, o da tese, comutável, com maior ou menor grau de conservação semântica, às outras classes de peritextos. Nesse sentido, a arte de elaboração do texto de resumo se torna extremamente complexa, e tal complexidade deveria atentar à responsabilidade do pesquisador, sobretudo para viabilizar a relevância de pesquisas como essa.

Assim, da inviabilização do acesso interpretativo do arquivo textual das teses de design, considera-se que a melhor opção seja a elaboração de um arquivo de resumos das referidas teses. Este estoque peritextual apresenta prejuízos semânticos em relação a sua situação de coadjuvância textual, porém, tal prejuízo, é bom que se afirme, advém sobretudo das competências de redação dos pesquisadores autores das teses. Tais competências deveriam implicar em textos operados por um exigente exercício de metalinguagem que pudesse explicar o rigor teórico-prático do campo pela vigência da ética científica, o que, de qualquer modo, não cabe aqui, neste momento, avaliar.

A tarefa de uma análise de conteúdo do plano semântico dos resumos é absolutamente viável, no entanto, a partir do reconhecimento do crescente grau de opacidade deste plano, cuja transparência total só poderia se dar, quiçá, por aprofundadas análises das estruturas semânticas, opta-se, arriscadamente, em utilizar de recursos bibliométricos que sejam capazes de capturar a emissão distributiva dos principais termos, por número cardinal de repetição de aparições, aparições correlatas e do valor de ligações entre as aparições das palavras de maior relevância semântica (os substantivos) dos resumos das teses. A emissão distributiva relevada pelas constelações de termos pode, assim, revelar a cardinalidade de uso deles e a ordem de relevância de suas concatenações parciais. Logo, a sintagmaticidade dos resumos ainda se conserva pelas linhas de conexão entre as palavras, embora perca seu caráter evidentemente gramático de ordenamento, isto é, a gramática fica subssumida pelas conexões que interligam as palavras na formação constelar do diagrama, e a paradigmaticidade fica sugerida pelo grau de vizinhança entre os termos demonstrados no resumo original e considerados pertinentes na nebulosa de palavras. De acordo com esse método, será possível sinalizar quais sejam os paradigmas dominantes, bem como os emergentes (ainda que marginalmente mínimos), que articulam a concatenação sintagmática das pesquisas em design?

\subsection{Como Produzir os Diagramas no Software VOS Viewer}

A tarefa de tornar legível os sintagmas dos resumos das teses exigiu o hackeamento daquilo que a ferramenta é programada a ler (arquivos que provém de bases bibliométricas). Neste processo, foram exploradas as tipologias de arquivo que o VOS Viewer reconhece, mantendo o rigor do quão fidedigno seria converter os sintagmas dos resumos em um destes arquivos legíveis pelo software. Após tentativas e erros, foi selecionada a extensão $\mathrm{CSV}^{9}$ por mostrar-se eficiente para a tarefa.

\footnotetext{
${ }^{9}$ CSV significa "comma-separated values" (valores separados por vírgula). Em síntese, são arquivos de texto de formato regulamentado pelo RFC 4180, que faz uma ordenação de bytes ou um formato de terminador de linha, separando valores com vírgulas, sendo comumente usado em softwares de produtividade tais como o Microsoft Excel e o LibreOffice Calc.
} 
Depois de gerado o CSV, o passo inicial é selecionar a opção de criar um mapa com uma base de dados no VOS Viewer ${ }^{10}$. Ao lidar com o número de aparições de uma palavra, precisa-se definir a estrutura do limite visualizado. Para a análise proposta neste artigo, foram escolhidas o mínimo de 5 ocorrências, principalmente porque 5 é o número apontado como ideal pela literatura bibliométrica como meio de análise (ZUPIC; ČATER, 2015). Ou seja, as 5 ocorrências não trazem todos os termos dos dados (o que ocorreria se fosse escolhida a variante 1) e também não excluem relações marginais importantes (o que acontece quando escolhida a variante 6 ou mais). É importante ter em mente que o número de ocorrências está diretamente relacionado a quantos termos marginais quer se evidenciar, e é sempre uma escolha das ênfases e abordagens que a pesquisa demanda.

Ao avançar pela base gerada das teses de design do Brasil, o VOS Viewer aponta que ao escolher um número mínimo de 5 ocorrências de um termo, reduzimos o total de termos de 19437 para 614. No entanto, o presente artigo - que se coloca como abertura inicial de um diálogo a partir das possibilidades que essa utilização do VOS Viewer oferece à comunidade acadêmica - está menos interessado em discutir e visualizar os termos de maior ocorrência na área do que em discutir a emergência das temáticas de menor ocorrência. Dessa forma, foi realizada uma segunda rodada de seleção de termos na qual foram excluídos da contagem os termos com mais de 25 ocorrências, de maneira a dar visibilidade aos termos que costumam ser negligenciados nas visualidades de maior ocorrência. Ou seja, ficou-se com o intervalo que vai de 5 a 25 ocorrências.

Posteriormente, uma pontuação de relevância é calculada, para cada termo, a partir de suas coocorências em um mesmo sintagma, ou seja, quantas vezes um mesmo termo aparece no resumo de uma tese. A relevância então contabiliza as coocorências de um termo em todos os sintagmas (em todos resumos que compõem a base de dados). Finalmente, os termos mais relevantes são selecionados e correlacionados entre si. Por padrão, $60 \%$ dos termos mais relevantes geram os mapas, de maneira a viabilizar a leitura das imagem, caso contrário, o seu nível de complexidade tende a tornar o diagrama ilegível. (VAN ECK; WALTMAN, 2014). Nesse caso, obteve-se um total de 400 conexões geradas que mostram quais termos estão próximos uns dos outros, considerando todos os resumos. Além destes parâmetros, que se dão todos por repetição, o VOS Viewer ainda permite uma depuração dos termos. Nessa direção, logo no início do processo retiramos todas as expressões que perdem sua significação na lógica do software e que, nessa situação, tornam-se pouco reveladoras, ou até mesmo ilegíveis, para compreensão das temáticas de teses do Brasil ${ }^{11}$. O diagrama que emerge dessa seleção é discutido na próxima seção.

\footnotetext{
${ }^{10}$ Escolher "criar um mapa com base em dados de texto" ("create a map based on text data";); em seguida "Ler dados dos arquivos do visualizador VOS" ("Read data from VOS viewer files") e navegar pelos arquivos para selecionar o CSV para o qual deseja importar os dados. Você será solicitado pelas seguintes questões: manter "rótulos de resumo estruturados" e manter "declarações de direitos autorais" ("structured abstract labels" e "copyright statements"). Dizer sim a ambos. Antes de avançar, escolher "contagem total" ("full counting").

11 Os termos e expressões retirados foram: desenvolvido, rio, utilizado; critério; abordagem; estado; foi; bibliográfica; que se; desenvolver; compreender; janeiro; dificuldade; capaz; consequência; entanto; pais; tendo; vinculado; geral; porém; início; assim como; investiga; acerca; puc rio; e o; entretanto; após; período; ainda; contribuição; quanto; discussão; desenvolvida; com vista; neste sentido; capitulo; line; foi realizado; buscou; foram; neste contexto; nesta pesquisa; analisado; identificado; definido; caráter; mai; estatese; poroutrolado; trata-se; captura; XIX; uso de; linha; nesta tese; utilizou; finalmente; propõe-se; nesse contexto; podem; noção; direcionado; apo; constituem; então; tese e; importante; mesma; que o; onde; contribuição; especificamente; conclusão; sugesto; estabelecido; apesar; por sua; poi; trajetória; III; seguinte; produzida; presente tese; foi realizada; nos curso; segunda; muitas veze; empregado; maioria da; visando; deste modo; inicialmente; ambos; entre outro; segundo; apresentamos; os ano; preferencia; como o; escolha; neste caso; tais como; dividido; os resultados obtidos; auxilio; ante; identificado; vista; hoje; uso e; guia; decorrer; dentre; niveis; partir da; geralmente; alcance; possiveis; edição; presente trabalho; trânsito; foram analisadas; expectativa; carta; parceria com; distância; maneira como; esta tese investiga; navegação; desse modo; utilizando-se; estas; durante; sendo assim; seguir; para além; instrução; já que; na sequência; presente pesquisa; elaboração; entre eles; partindo; logo; carga; por isso; conclui-se que.
} 


\section{Os Diagramas como Legi-Signos Indicativos Remáticos: temáticas emergentes da pesquisa em design.}

Como descrito na seção anterior, o VOS Viewer foi utilizado para tornar visível as temáticas emergentes que, aparentando escapar de discussões status quo da pesquisa em design, indicam as temáticas de menor ocorrência que podem inspirar e apontar caminhos futuros aos pesquisadores em formação. O Gráfico 1 ilustra essa distribuição mais difusa.

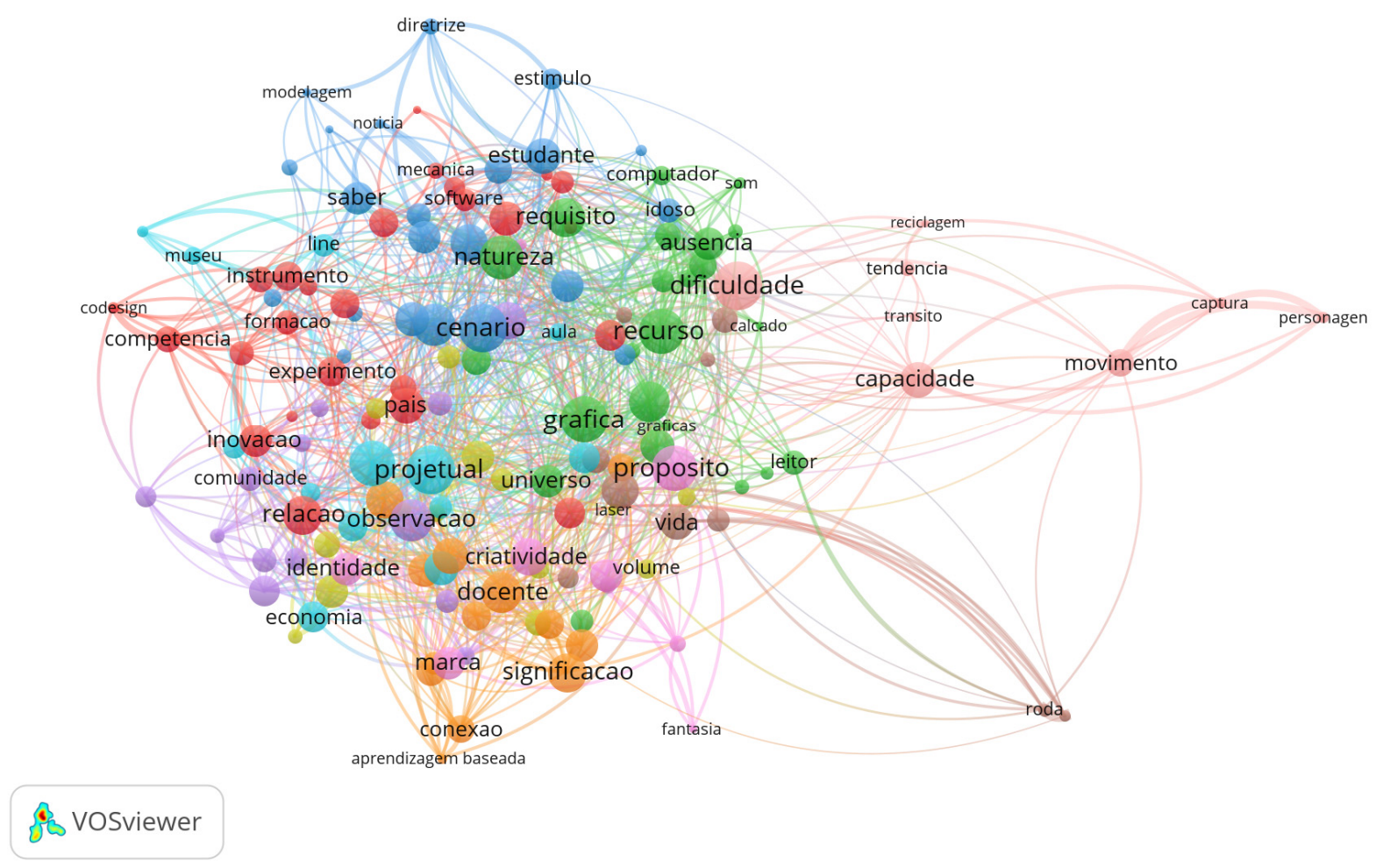

Gráfico 1: Temáticas emergentes (entre 5 a 25 ocorrências) das teses de design do Brasil

O diagrama do Gráfico 1 configura uma nuvem de palavras consideradas relevantes dentro de um elemento peritextual das teses ${ }^{12}$. Evidencia-se, por ocorrência, um primeiro plano com termos maiores e em centralidade na complexa rede formada pelo algoritmo: projetual, cenário, recurso, propósito, dificuldade e gráfica. Poderíamos, ainda pela ocorrência, apontar um segundo plano em que

12 Os termos e expressões mantidos foram: acessibilidade, ambiente construído, aplicativo, aprendizado, aprendizagem baseada, artesanato, atenção, aula, ausência, auxílio, cadeira, calçado, capacidade, captura, caráter, cenário, cinema, codesign, competência, computador, comunidade, conexão, consumidor, core, corpo,cotidiano, criatividade, cultura material, desenho, design editorial, dificuldade, dinâmica, diretriz, discurso, diverso, docente, ead, economia, eficácia, eficiência, elaboração, embalagem, emergência, empregado, engenharia, ensino aprendizagem, espaço público, estímulo, estudante, evolução, existência, experiencium, experimentação, experimento, fabricação, fantasia, feedback, fenômeno, formação, fotografia, framework, funcionalidade, geometria, gestão de design, governo, gráfica, gráficas, habilidade, idade, identidade, idoso, ilustração, impresso, indivíduo, inovação, instrumento, laboratório, laser, leitor, line, linha, lógica, logo, lugar, marca, mecânica, mecanismo, medium, melhoria, mobiliário, modelagem, movimento, mudanças, mundo, museologia, museu, natureza, notícia, observação, organização, ótica, paciente, painel, pais, panorama, paradigma, percurso, personagem, pesquisa ação, planejamento, plano, poder, política, prática projetual, presença, processo criativo, programa, projetual, propósito, realidade, reciclagem, recurso, rede, reflexão, registro, relação, reprodução, requisito, resistência, resposta, revista, roda, saber, satisfação, semiótica, serviços, setor, significação, software, som, sucesso, sul, tarefa, tela, tendência, trajetória, transformação, trânsito, universo, vida e volume. 
se destaca docente, significação e propósito, ou avançar no Gráfico 1 até percorrer todos os termos legíveis. Destaca-se as ordens que eles assumem a partir de sua coocorrência e relevância: significação, docente, propósito e dificuldade se sobressaem por trazerem à visualidade a força de ligação entre eles e demais termos, expressos pelas conexões entre si e pelo padrão cromático.

No entanto, à diferença dos resumos, que figuram na classe do legi-signo símbolo dicente, a imagem gerada pelo VOS Viewer, e expressa no Gráfico 1, modifica a sua classificação semiótica no que remete à sexta classe definida por Pierce (1984), chamada legi-signo indicativo remático. Conforme já comentado, a sexta classe também comporta em menor medida a sua anterior, a quinta, que é o legi-signo icônico remático. A quinta classe consiste em uma lei que governa réplicas singulares e, por ser um ícone, é também um rema. Ou seja, como coloca Peirce, o legi-signo icônico remático exige que cada uma de suas aparições "incorpore uma qualidade definida que o torna apto a despertar, no espírito, a idéia de um objeto semelhante" (1984, p.106). Já a sexta classe é uma lei que exige que cada caso seja efetivamente afetado por seu objeto, ou seja, que direcione a atenção ao objeto (PEIRCE, 1984).

Nesse sentido, o diagrama é um legi-signo indicativo remático pois direciona à atenção do interpretante para três qualidades que advém do seu objeto, ou seja, dos resumos das teses: (i) a frequência das ocorrências, no sentido em que os termos que aparecem marcados por esferas de maior tamanho são aqueles que possuem maior frequência de ocorrências (por exemplo, o termo projetual) e, consequentemente, os de menor tamanho são os que possuem menos ocorrências (por exemplo, o termo fantasia); (ii) a relevância, ou seja, a frequência de coocorrência entre os termos ao longo de todos os sintagmas, que é expressa pelas cores das esferas ${ }^{13}$, sendo que os termos de maior relevância se aproximam de cor amarela (ex.: o termo volume) e os de menor relevância se aproximam da cor azul (ex.: o termo economia); e (iii) a proximidade entre os termos ao longo de todos os sintagmas, que é expressa, de forma aproximada, pela proximidade espacial das esferas (termos) na imagem. (VAN ECK; WALTMAN, 2014).

Vale mencionar que, para o interpretante, o diagrama também é um legi-signo icônico remático na medida em que desenvolva nele outro(s) signo(s), de maior ou menor complexidade, que se assemelham ao diagrama (como, por exemplo, a lembrança de uma tese específica, uma discussão em aula, um outro diagrama ou qualquer imagem que lhe apareça à mente daquela derivada).

Ainda, é possível, no Vos Viewer, navegar pelo diagrama do Gráfico 1, entendendo quais são as palavras que aparecem relacionadas entre si nos resumos das teses. Nessa direção, o Gráfico 2 ilustra a seleção do termo projetual, que é o termo que possui o maior número de conexões (56) com outros termos, no recorte de termos expresso no Gráfico 1.

Embora o diagrama do Gráfico 2 também seja afetado pelos resumos da tese pela frequência (tamanho das esferas), pela coocorrência (as cores ${ }^{14}$ ), pela conexão entre as esferas e pela proximidade das esferas, não é possível - e nem mesmo sugere-se - significar essas conexões (traços que ligam os termos). Nesse sentido, o diagrama perde os nexos sintagmáticos dos resumos e, por isso, sua leitura, embora alcance um panorama geral, torna-se semanticamente muito mais precária, o que desmente a

\footnotetext{
13 As cores apresentadas nas visualidades deste artigo são as cores padrão do VOS Viewer. De acordo com o manual de uso da ferramenta, explica-se a lógica de definição cromática das visualidades em uma sobreposição pela sua pontuação. Quer dizer, é pela pontuação de um termo que sua cor é determinada. Se um termo tem pontuação pela relevância (frequẽncia dos termos em coocorrênia em todo o sintagma) sua apresentação na visualidade seguirá por uma variação que inicia em azul (pontuação mais baixa) a verde para amarelo (pontuação mais alta), e acontece em duas etapas. Na primeira etapa, a pontuação de um termo é transformada em um valor de cor. Uma pontuação entre as pontuações mínimas e máximas especificadas podem ser definidas, mas seja como for é transformada linearmente em um valor de cor entre 0 e 1 . Uma pontuação abaixo da pontuação mínima ou acima da pontuação máxima é transformado em um valor de cor de 0 ou 1 , respectivamente. $\mathrm{Na}$ segunda etapa, a cor de um item é determinado combinando o valor da cor do item com as cores definidas pelo arquivo de definição de cores (que pode ser modificada pelo usuário, se for de seu interesse adotar outro padrão cromático). A correspondência exata de valores de cor geralmente não é possível. A cor de um item é então determinada pela interpolação entre duas cores em um arquivo de cores de sobreposição.

${ }^{14}$ Vale relembrar que as cores dizem respeito as relevâncias da totalidade do Gráfico 1.
} 
hipótese questionada no final da seção 2.2. Apesar de que não se recomende arriscar qualquer tipo de leitura entre os termos, é necessário recorrer a oitava classe de signos de Peirce (1984), a que define o símbolo remático (legi-signo símbolo remático) ${ }^{15}$ para explicitar a leitura semiótica que cada um dos termos torna possível.

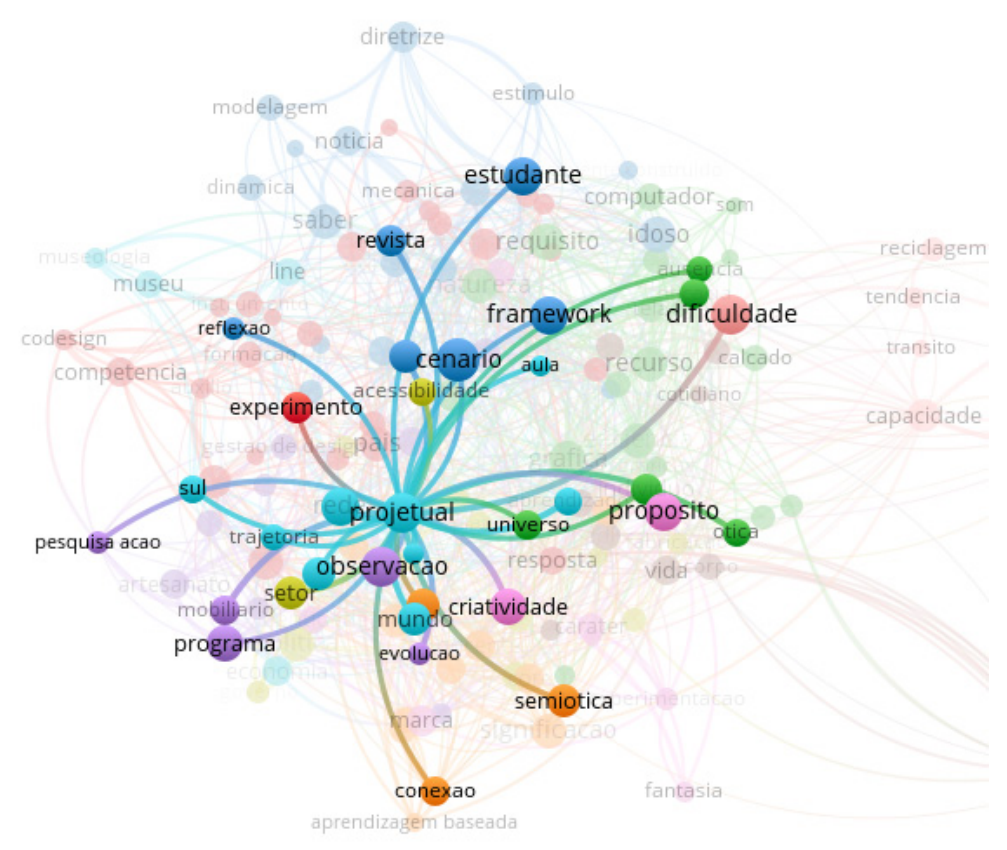

Gráfico 2: Destaque para o termo projetual (56 conexões).

Como símbolo remático (que o próprio Peirce exemplifica como sendo um substantivo comum), cada um dos termos é um signo que, por meio de uma associação de ideias gerais, relacionase com seu objeto, de maneira que "sua Réplica desperta uma imagem no espírito, imagem que, devido a certos hábitos ou disposições daquele espírito, tende a produzir um conceito geral, sendo a Réplica interpretada como Signo de um Objeto que é um caso daquele conceito" (PEIRCE, 1984, p. 106). Por sua vez, as réplicas de um símbolo remático configuram a terceira classe de signos peircianos, o sinsigno indicativo remático, que é uma ocorrência singular que chama atenção para o objeto do qual decorre sua presença.

Sendo assim, o termo projetual que aparece no Gráfico 2, embora seja um adjetivo quando concatenado em um sintagma textual, também se comporta como um sin-signo indicativo remático, na medida em que desperta aos seus interpretantes uma associação de ideias gerais referentes às cercanias semânticas do substantivo comum denominado projeto. Aqui, tem-se uma consideração de extrema importância: a ideia que o termo projetual desperta em cada um de seus interpretantes (como por exemplo vocês, leitores, ou nós, autores do artigo) depende de suas crenças, hábitos e disposições mentais que orientam o processo de interpretação, logo, de leitura e compreensão dos diagramas, não podendo assegurar qualquer tipo de precisão ou mesmo de existência real em sua significação, por mais que as teses de origem tentem, exatamente isso, asseverar. Como um rema, é um signo de mera possibilidade de realidade.

Nesse sentido, os termos do diagrama podem não possuir, necessariamente, o rigor metalinguístico exigido pela ética científica. Esse rigor só pode ser alcançado com uma leitura atenciosa de cada uma das teses por um espírito que seja capaz de reconhecer o ordenamento

\footnotetext{
15 "O Interpretante de um Símbolo Remático com frequência o representa como Legi-Signo Indicativo Remático; outras vezes, como Legi-signo Icônico; e, com efeito, e em reduzida porção, ele participa da natureza de ambos." (PEIRCE, 1984, p. 107).
} 
epistemológico com o qual os termos são empregados ${ }^{16}$. Sem mais aprofundamentos que não cabem no espaço do debate teórico-metodológico proposto por este artigo, termina-se, por aqui, a discussão das possibilidades de significação dos diagramas das temáticas de pesquisa de design no Brasil, para convidar o leitor a algumas reflexões finais.

\section{Para Onde Podemos (e Desejamos) Ir?}

Esse artigo se ocupou de explicar o caminho percorrido para geração de um diagrama das temáticas emergentes de todas as teses em design no Brasil publicadas até agosto de 2019. No entanto, ressaltase que a lógica do software VOS Viewer coloca algumas limitações referentes não apenas à leitura semântica dos termos destacados, mas também à própria visualização dos termos de menor ocorrência e, por tanto, emergentes. Nessa direção, vale lembrar algumas escolhas e restrições que se colocam: os diagramas apresentados nesta pesquisa mapearem apenas os termos que se encontravam em um intervalo de 5 a 25 ocorrências ao longos dos resumos das teses e que, deste total, apenas $60 \%$ aparecem na visualidade. Isso significa que podem existir termos que apontam para temáticas emergentes, mas que, por enquanto, possuem menos de cinco ocorrências. Além disso, $40 \%$ dos termos menos relevantes não ficam visíveis no diagrama, ou seja, são termos que aparecem mais de 5 vezes nos sintagmas mas não tem uma pontuação elevada de coocorrência.

Em relação às limitações semânticas, é importante dizer que, com estes diagramas, dispõem-se como que de um caça-palavras às avessas, pois o que se tem são as palavras, na sua materialidade de ocorrência sensível, de aparição imagética para-ideal, todavia, faltam-lhes os enunciados ordenadores, ou seja, seus paradigmas teórico-metodológicos.É nesse sentido que esta pesquisa se colocou, à caça do sentido dos temas que dominam o regime textual do campo de pesquisa em design no Brasil, à caça da orientação ideal das variações das aparições das palavras, da predominância de uma frequência de uso em detrimento de outras, do surgimento de novas e do declínio das antigas, pois há também a possibilidade de leitura de eixos de mutação temporal sobre os usos dos termos em relação à sua atualização no corpus dos textos considerados. Em termos peirceanos, a semiose do interpretante é sempre uma emergência temporal e, portanto, passível de transformações.

Como pontua a citação de Ítalo Calvino no início do artigo, o diagrama gerado oferece uma sensibilização inicial que, por um lado, revela-se precária em relação à compreensão do sentido das temáticas emergentes nas teses de design do Brasil (VAN ECK; WALTMAN, 2014), por outro, disponibiliza uma alto potencial de sugestão significante, cabendo ao leitor precaução no uso deste método caso queira extrair conclusões que ele não torna evidente. Nesta direção, recomenda-se à leitura completa da(s) tese(s) que possam despertar-lhe o interesse. Convida-se também os pesquisadores em design do Brasil a construírem com rigor metalinguístico suas temáticas e, para isso, considera-se necessário uma compreensão aprofundada de seus paradigmas teóricos-metodológicos. Isso torna possível a reinvenção de temáticas consolidadas conservando o rigor científico no tratamentos das temáticas emergentes. Por fim, sugere-se que futuras pesquisas podem especular acerca de outras possibilidades de uso do VOS Viewer na geração de diagramas, bem como sobre a utilização de outros softwares bibliométricos.

\footnotetext{
${ }^{16}$ Nesse sentido, a noção de Metadesign desenvolvida por Bentz e Franzato (2017) pode auxiliar na constituição de um ordenamento epistemológico em diferentes níveis semânticos para o campo da pesquisa em design.
} 
Enabling diagrammatic readings of thesis abstracts: hunting-meaning of design research in Brazil

Abstract: Between 2004 and 2019, design graduate programs in Brazil granted PhD titles for 423 students. What were those theses about? What themes did they develop? Based on terms that emerges on their abstracts, this article adopts VOS Viewer bibliometric tool to, beyond its conventional usage possibilities, generate diagrams of the themes that are less recurrent in these abstracts, aiming to escape the dominant discussions in the design area. Therefore, the article advances in a semiotic classification and discussion about both the abstracts and the visualities found. Finally, these maps are understood as initial sensitizations, indexes that make emerging themes visible which can inspire and point out other avenues of design research to researchers in formation.

Keywords: graduate program in design; semiotics; diagram; bibliometry; peritext

\section{Referências Bibliográficas}

BENTZ, Ione M.; FRANZATO, Carlo. The relationship between Strategic Design and Metadesign as defined by the levels of knowledge of design. Strategic Design Research Journal, v.10, n. 2, 2017.

CALLON, Michel et al. From translations to problematic networks: An introduction to co-word analysis. Information (International Social Science Council), v. 22, n. 2, p. 191-235, 1983. DOI: $10.1177 / 053901883022002003$

CALVINO, Italo. Se um viajante numa noite de inverno. Tradução de Nilson Moulin. São Paulo: Companhia das Letras, 1999.

GENETTE, Gérard. Paratextos Editoriais. Tradução de Álvaro Faleiros. São Paulo: Ateliê Editorial, 2009.

GENETTE, Gérard. Palimpsestos: a literatura de segunda mão. Belo Horizonte: Edições Viva Voz, 2010.

GENETTE, Gérard. The Architext: an Introduction. translated by Jane Lewin. Berkeley and Los Angeles, California: UCLA Press, 1992.

PEIRCE, Charles. S. Semiótica e Filosofia. Tradução de Octanny Silveira da Mota e Leonidas Hegenberg. São Paulo: Editora Cultrix, 1984.

VAN ECK, Nees Jan; WALTMAN, Ludo. VOSviewer manual. Leiden: Universiteit Leiden, v. 1, n. 1, p. 1-53, 2013.

VAN ECK, Nees Jan; WALTMAN, Ludo. Visualizing bibliometric networks. In DING, Ying.; ROSSEAU, R.; WOLFRAM, Dietmar (Eds.), Measuring scholarly impact: Methods and practice. Springer, 2014. p. 285-320.

ZUPIC, Ivan; ČATER, Tomaz. Bibliometric Methods in Management and Organization. Organizational Research Methods, v.18, n.3, p. 429-472. 2015. DOI: 10.1177/1094428114562629 